\title{
Analysis of Long Time Series of ADCP Backscatter Data in the Ligurian Sea to Investigate the Zooplankton Variability
}

\author{
Elisabetta Schiano, Sara Pensieri, Roberto Bozzano \\ National Research Council \\ Genoa, Italy
}

\author{
Paola Picco \\ Italian National Agency for New Technologies, Energy and \\ Sustainable Economic Development \\ La Spezia, Italy
}

\begin{abstract}
Three years of $300 \mathrm{kHz}$ Acoustic Current Doppler Profiler ancillary data collected in the Central Ligurian Sea are analyzed to investigate the zooplankton diel vertical migration in the upper thermocline. After a pre-processing aimed at avoiding the slant range attenuation, hourly volume backscattering strength time series were obtained. Despite the lack of concurrent net samples collection, different migration patterns were identified and their seasonal variability examined by means of time-frequency analysis. Relationships with environmental conditions and lunar phase were also evidenced.
\end{abstract}

Keywords - Acoustic Doppler Current Profiler, zooplankton diel vertical migration, Ligurian Sea

\section{INTRODUCTION}

The diel vertical migration (DVM) is a vertical displacement performed by most species of zooplankton. Many different patterns of DVM have been reported in literature, but the most common observed one is the swimming upward at sunset and downward at sunrise. Although the causal factors are still not completely known, a lot of studies indicate that this observed behavior and its great variability are influenced by several environment causes, as light, temperature, food and predation pressure, as well as by endogenous origins, like sex and age.

Studies of DVM are usually carried out using net tows or pump samples for determining the vertical distribution of the zooplankton. These methods allow to identify the different species but their sampling is lacking of detailed information on the temporal variability, especially on the longer time scale.

Improve the knowledge on DVM is important not only for the marine biologists but also for the physical oceanographers, given that this signal may produces a noise on the vertical current measurements [1][2][3][4][5][6]. A great contribution to the investigations on this topic, may be given by the Acoustic Doppler Current Profiler (ADCP). This instrument estimates the marine currents through measuring the Doppler shift of particles moving into the water column. At the end of 1980's, some studies [7][8] showed that the acoustic backscatter signal obtained by ADCP is correlated with the zooplankton biomass. Since then, the ADCP has been widely employed by marine biologists also. In order to convert the backscatter intensity to equivalent zooplankton biomass, the ADCP data are often calibrated against coincident data from net samples. Nevertheless, this calibration method is somewhat problematic and the resulting relationship provides only rough estimates [2][5][9]. Consequently, ADCP data are mainly used in qualitative studies. In spite of this significant limitation, data provided by ADCP allow to acquire important information because the instrument once deployed perform long term monitoring in all weather condition with a high temporal resolution that is not possible to obtain using any other method. For this reason, a re-examination of existing long temporal series of ADCP data can contribute to enhance the zooplankton knowledge [2].

With this aim, the echo intensities and vertical velocity data obtained from an ADCP moored in the open Ligurian Sea from September 2003 to February 2006 were analyzed in terms of variations in the zooplankton vertical migration.

\section{DATA}

From 13 September 2003 to 22 February 2006 an upwardlooking RDI Workhorse Sentinel $300 \mathrm{kHz}$ ADCP was moored in the Central Ligurian Sea $\left(43^{\circ} 47.77^{\prime} \mathrm{N} ; 9^{\circ} 02.85 \mathrm{E}\right)$ for three distinct experiments focused on the upper layer current variability in that area [10].

The first experiment took place from 13 September 2003 to 24 May 2004 and the ADCP was set for sampling the upper 48 $\mathrm{m}$ of water column with $8 \mathrm{~m}$ vertical resolution and a sampling time interval of 1 hour. In the second experiment, from 23 September 2004 to 15 April 2005, the instrument was moored to investigate the water column to a depth of $90 \mathrm{~m}$, with the same spatial and temporal resolution previously adopted. During the third experiment, the maximum depth examined was $-70 \mathrm{~m}$ with $8 \mathrm{~m}$ vertical resolution and 30 minutes sampling time.

In all three deployments, the ADCP was set to perform data ensemble of 55 pings average.

For each deployment, in order to check the vertical displacement of the mooring, both pressure measurements from a CTD device installed close to the ADCP and the distance of the ADCP to water surface were used following Visbeck and Fischer [11]. 
The moorings showed good stability, with pitch and roll data never exceed $2.5^{\circ}$, well below the threshold for tilt compensation, and a standard deviation lesser than $1^{\circ}$, satisfying the requirements for good velocities data [12].

The signal/noise ratio was above 10 during almost all the period of measurements [13].

All observations were quality checked and the percentage of data rejected is lesser than $0.1 \%$. Thus, the overall ADCP dataset consists of 11063 hourly data and 14934 measurements with a sampling time of 30 minutes.

\section{METHOD}

The measurement of the echo intensity scattered by the ocean is usually given in terms of volume backscattering strength $(\mathrm{Sv}) \mathrm{dB}$ re $(4 \pi \mathrm{m})^{-1}$. Following Deines [14], it is computed for each depth cell along each of the four beams as in

$$
S v=C+10 \log _{10}\left(\left(T_{x}+273.16\right) R^{2}\right)-L_{D B M}-P_{D B M}+2 \alpha R+K_{c}(E-E r)
$$

where $C(-143.5 \mathrm{~dB})$ is an instrumental constant of RDI profilers for Workhorse Sentinel ADCP $300 \mathrm{kHz}$. $T x$ is the ADCP internal temperature in ${ }^{\circ} \mathrm{C}$. $L_{D B M}$ is the $10 \log _{10}$ of the transmit pulse length in $\mathrm{m}$ (8.21 $\mathrm{m}$ for all three deployments). $P_{D B M}$ is the $10 \log _{10}$ of the transmit power in Watt defined by RDI for the ADCP model here used as $14 \mathrm{dbWatt} . E$ is the echo intensity provided by the ADCP, $\operatorname{Er}$ (40 counts) is the echo reference value when there is no signal specifically determined for each instrument. $K_{c}$ is the factor for converting to $\mathrm{dB}$ unit the raw echo data provided by the ADCP and it is defined following the WinRiver user guide [12] as in:

$$
K_{c}=\frac{127.3}{T_{x}+273}
$$

$\alpha$ is the sound absorption coefficient for the seawater that is variable with depth and it is computed according to Ainslie and McColm [15] formula, a simple expression which takes into account the contribution of Boric Acid, Magnesium Sulfate and pure water and depends on temperature and salinity. These last two parameters are obtained from the climatologic MED6 data base, a gridded monthly mean of in situ measurements of temperature and salinity for the whole Mediterranean and the near North Atlantic area at $1 / 4^{\circ}$ resolution [16]. Data from the MED6 data base are selected in a $0.25^{\circ}$ square centered on $9.375^{\circ} \mathrm{E} ; 43.75^{\circ} \mathrm{N}$, the grid point closest to the mooring.

$R$ is the slant range to the scatters in meters expressed by:

$$
R=\frac{B+\left(\frac{L+D}{2}\right)+[(n-1) D]+D / 4}{\cos \vartheta} \frac{C^{\prime}}{C_{1}}
$$

where $B$ is the blank in meters $(1.76 \mathrm{~m}$ for all deployments), $L$ is the transmit pulse length in meters, $D$ is the depth cell length in meters ( $8 \mathrm{~m}$ for all deployments), $n$ is the depth cell number of the scattering layer being measured, $\theta$ is the beam angle in degrees $\left(20^{\circ}\right) . C_{l}$ is the speed of sound in the water used by the ADCP and it is set to $1475.1 \mathrm{~m} / \mathrm{s}$, while $C^{\prime}$ is the average sound speed from the transducer to the range cell that depends on the depth and is computed by means of
MacKenzie formula [17] using the same MED6 data previously extracted and interpolated at a vertical resolution of $1 \mathrm{~m}$ from 0 down to $100 \mathrm{~m}$.

To be used in (1), the slant range should not be less than $\pi R_{0} / 4$, where $R_{0}$ is the Rayleigh distance defined by RDI for the Workhorse Sentinel $300 \mathrm{kHz}$ ADCP as $0.98 \mathrm{~m}$, and, according to Gordon [18], the maximum range of acceptable data $R_{\max }$ should be

$$
R_{\max }=H \cos \vartheta
$$

where $H$ is the distance of the instrument to the surface and $\theta$ the beam angle. In all three deployments both requirements are satisfied. Nevertheless, since the data close to the sea surface may be strongly affected by the atmosphere [19] they are not used in this analysis.

In the performed computation, $S v$ is the backscatter strength value obtained averaging the results of (1) applied to the four available beams.

Fig. 1 shows the averaged $\mathrm{Sv}$ profiles for the three deployments at different depths.

The results evidence that these values can be influenced by a low signal to noise ratio as pointed out by Gostiaux and Van Haren [20] who suggested to modify (1) as in:

$$
S v=20 \log _{10}(R)+2 \alpha R-A+10 \log \left(10^{k_{c} E / 10}-10^{k_{c} E_{r} / 10}\right)
$$

and to introduce the transmit lag $L a$ in (3), as in

$$
R=\frac{B+\left(\frac{L+D+L a}{2}\right)+[(n-1) D]+D / 4}{\cos \vartheta}
$$

In order to determine the constant $A$, a linear best fit between the $S v$ values obtained by Gostiaux and Van Haren equation and the $S v$ values calculated by the Deines formula is performed using only the bins that satisfy the test $k_{c}$ (EEr) $<10$.

Fig. 2 illustrates the behavior of the average $S v$ profile minus the value of the first bin as a function of the slant range using the Deines (cyan line) and the Gastiaux and Van Haren (red line) equation for all three deployments.

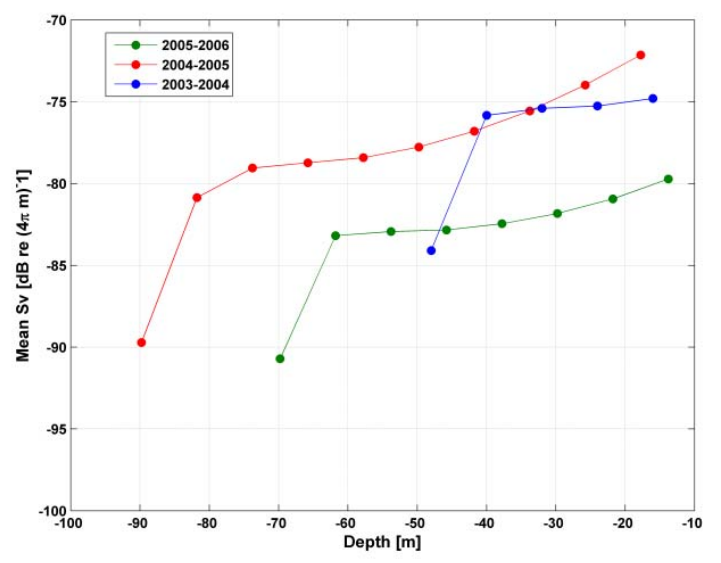

Fig. 1. Average backscatter strength profiles for the three deployments. 
In 2003-2004 data, the signal to noise ratio is very high for almost all acquired data, so that the improvement of the Gastiaux and Van Haren equation is limited to a quite constant little shift for all layers. On the contrary, in the 2004-2005 data,

the differences between the backscattering strength values computed by the two methods increase with the growing of the slant range. These become more marked for the data acquired in the third deployment for which the $S v$ values calculated by Deines equation tend rapidly to diverge from the ones obtained applying the Gastiaux and Van Haren expression already from the first two bins.

Furthermore, the closest bin to the transducer is characterized by a very weak signal and consequently the ADCP profile shows a high gradient on the second bin: this behaviour is due to the transient time needed by the instrument to transmit and receive the signal and the acquired data during this gap of time can be erroneous [21].

Taking into account the two previous issues, the $S v$ values considered for the analysis have been computed following Gastiaux and Van Haren expression and discarding the bin closest to the transducer.

\section{ANALYSIS}

The backscattering strength values obtained during the three deployments are shown in Fig. 3.

In the first deployment the measures are limited to the upper $50 \mathrm{~m}$ of the sea. From the beginning of the observational period in September 2003 to the first half of October, the mean daily backscatter strength values are high, particularly in the layers above $-30 \mathrm{~m}$. Starting from mid October until the first days of December 2003, they undergo to a significant decrease and slightly high values are recorded only sporadically under
$30 \mathrm{~m}$ depth. From mid December 2003, the signal begins to grow and the whole observed water column becomes substantially homogeneous. From mid April the measured values are again high even if only on a few occasions reach those recorded in October. A weak reduction appears in the surface layer shortly before the recovery of the mooring at the end of May 2004.

In the second deployment the water column is investigated up to $80 \mathrm{~m}$ depth. The mean $S v$ data collected above the $-35 \mathrm{~m}$ shows a similar trend to the one observed in the previous period 2003-2004: starting from mid October 2004 the values decrease until December when they start to grow slowly again to reach the highest values in April. However, in the layers above $-30 \mathrm{~m}$ the $S v$ values remain high during the whole time and the homogenization of the water column occurs only sporadically under $25 \mathrm{~m}$ depth until January 2005, when high signals begin to be registered even in the deepest layers. At the end of March, the $S v$ values are high at all depths.

Summer data are available only for the third deployment under very anomalous condition characterized by a long period of exceptionally calm condition of both marine and atmospheric dynamics. From mid June to the end of August the recorded $S v$ values are very low, especially below $30 \mathrm{~m}$ depth. A significant reduction of total zooplankton biomass in the summer months has been also reported in literature [22]. However, the mean daily backscatter strength data remains very low until mid February when a significant further drop is observed just before the end of the measurements.

Despite the significant interannual differences, all mean hourly backscattering strength values computed for the three deployments at the different depths show a marked daily cycle, with low values during the daylight and high ones in the night (Fig. 4).
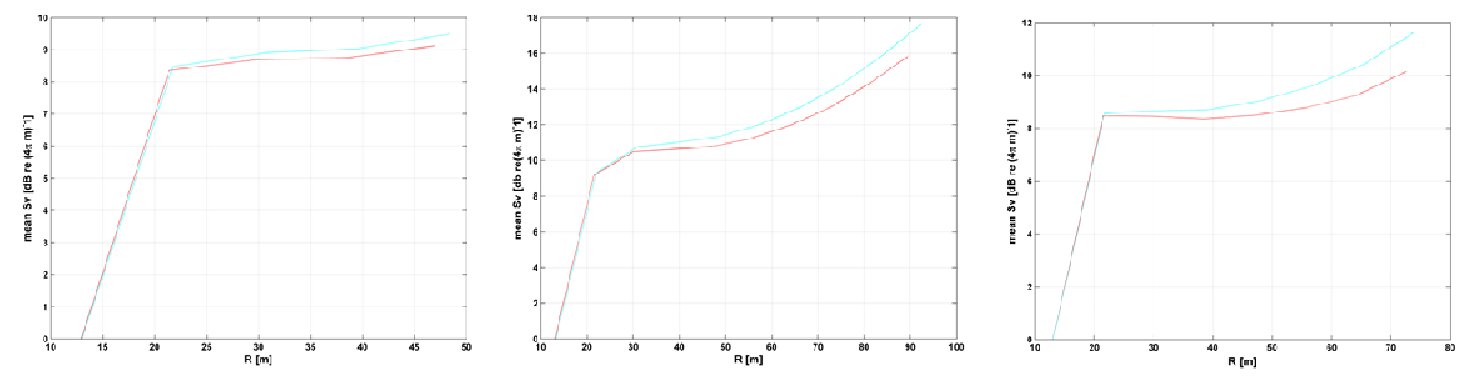

Fig. 2. Average Sv profile minus the value of the first bin as a function of the slant range for Deines (cyan line) and the Gastiaux and Van Haren (red line).

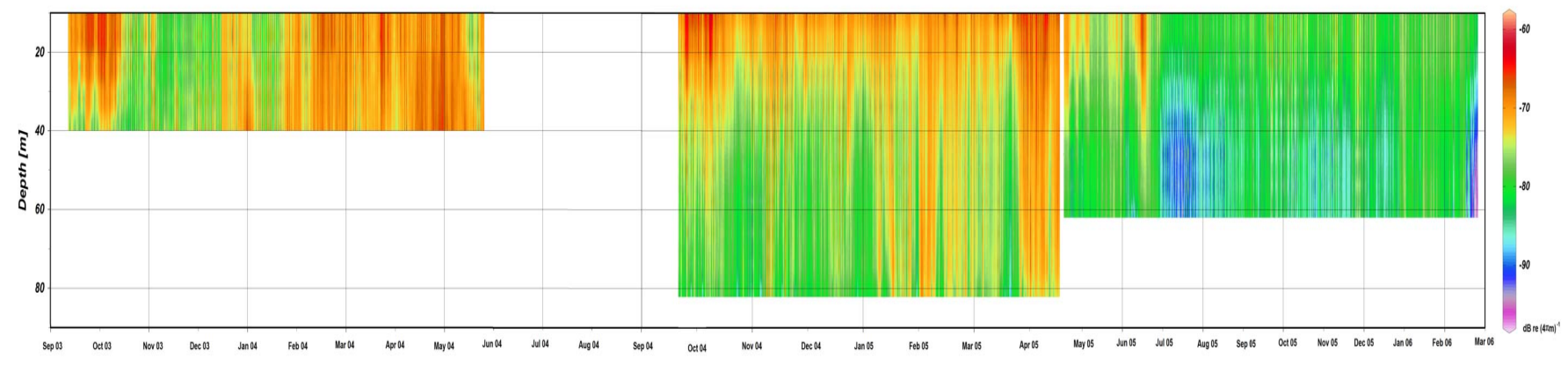

Fig. 3. Backscatter strength data recorded during the three deployments. 

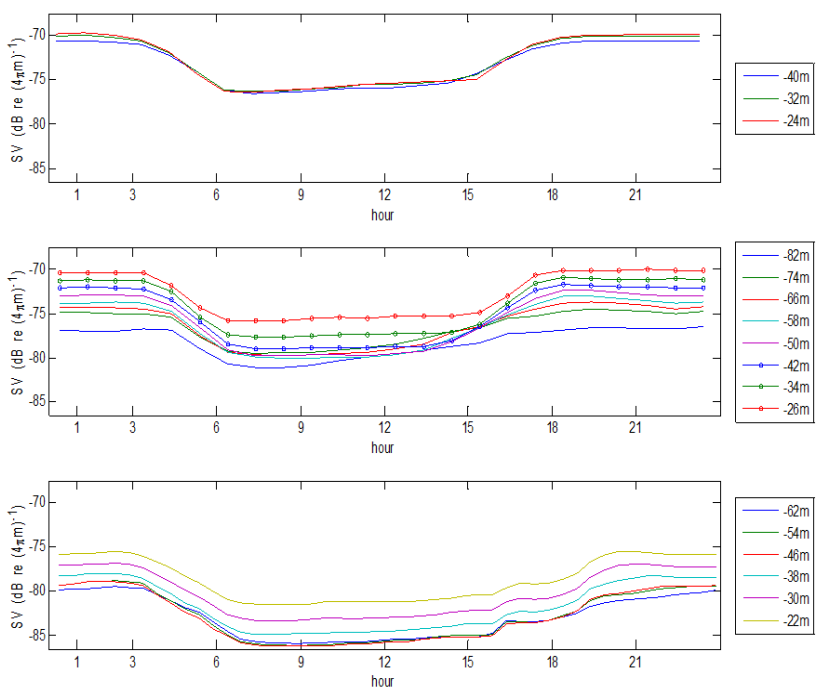

Fig. 4. Mean hourly values of Sv computed for the three deployments.

The same computation is performed for each month on both $S v$ and the vertical velocity obtained by the ADCP. Then, the time derivative $(\Delta S v)$ of the backscattering strength is estimated. The results show that the sudden changes in the $S v$ signal are associated with peaks in the value of the mean hourly vertical velocity, specifically negative peaks in the early morning and positive ones in the afternoon.

Furthermore, these changes mainly occur at the time of sunrise and sunset at the mooring position (Fig. 5).

The sunrise/sunset times at the mooring location are computed by using the air-sea toolbox developed at Woods Hole Science Center (http://woodshole.er.usgs.gov/operations /sea-mat/air_sea-html/index.html).

These results put in evidence the diel vertical migration performed by the zooplankton population. Specifically, they indicate that swimming upward at dusk and downward at dawn
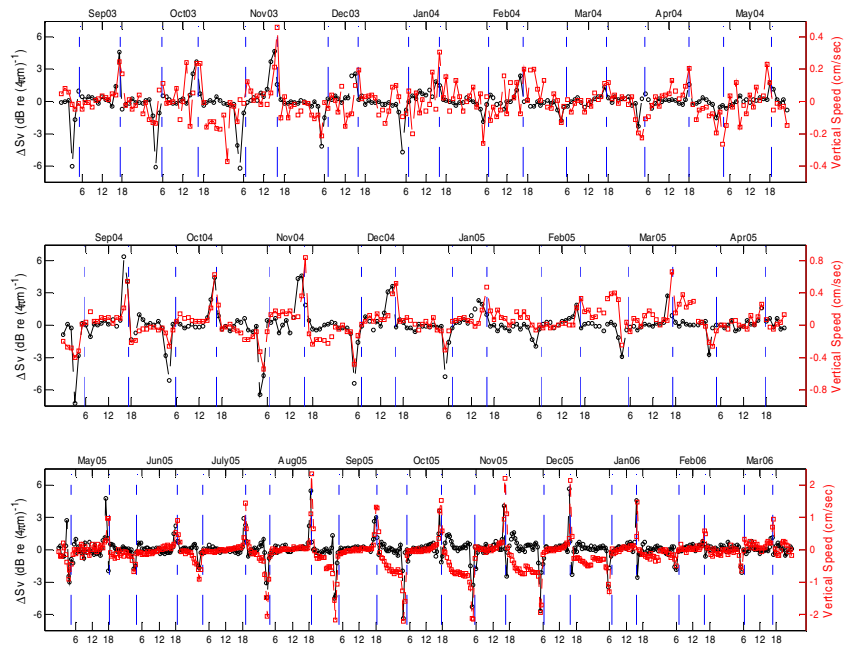

Fig. 5. Time derivative of Sv hourly values (black) and vertical speed (red) computed for each months for the three deployments at the common depth of $40 \mathrm{~m}$. Dashed blue line correspond to the sunrise and sunset time.

is the dominant pattern during all three periods. The signal is less marked during the winter months. However, also other patterns are observed (Fig. 6) as well as periods during which the vertical migration is not detected.

The spectral analysis performed on each time series confirms the prevalence of the 24-h cycle but also the presence of a second peak at $12-\mathrm{h}$. This signal may be associated to a different DVM pattern, the so called twilight migration characterized by two ascents and two descents every $24 \mathrm{hrs}$. This pattern is sometimes evident in the distribution of $S v$ values, especially in the data of the third experiment that have a higher temporal resolution.

In order to evidence the periods when the DVM is detected, a time-frequency analysis is performed. The spectrograms are computed using a 256 hours sliding window with a moving step of 24 hours. The results are shown in Fig. 7 for all three periods and for both the 24-h and 12-h cycles.

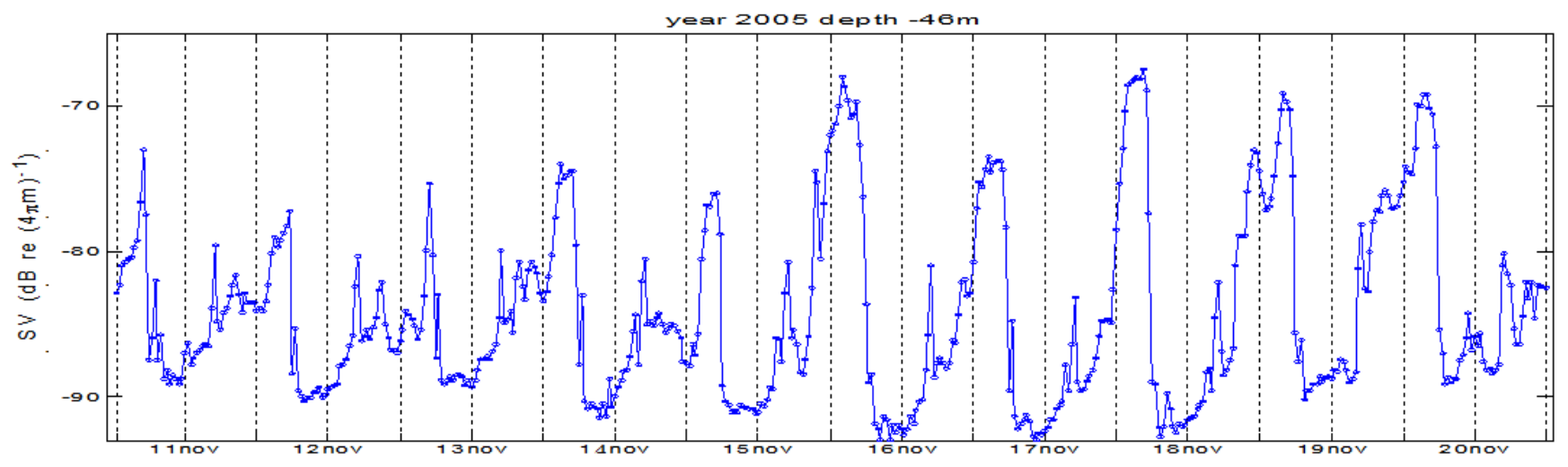

Fig. 6. Backscatter data measured from 11 to 20 November 2005 showing a peak a mid-afternoon. 

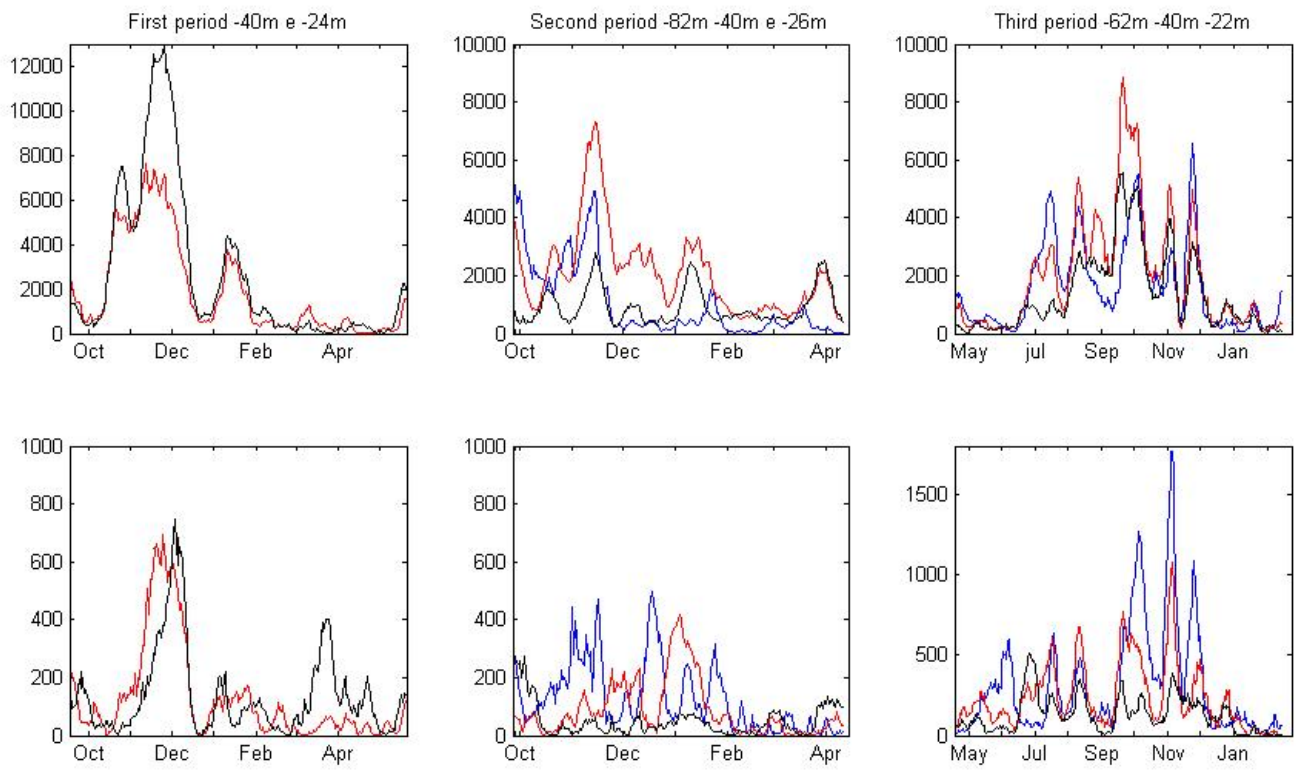

Fig. 7. Time evolution of the energy in the 24-h (upper panel) and 12-h (lower panel) bands for the three deployments at different depths, black line at the surface, red line at $-40 \mathrm{~m}$ and blue line at maximum observed depth.

The distributions show that both $24-\mathrm{h}$ and 12 -h cycles are more intense between the end of the summer and the beginning of the winter. The 12 -h cycle is less evident in the first and second deployments which have a lower temporal resolution. Furthermore, during the first deployment the maximum energy of the spectrum for the 24-h band is obtained for the surface layers, while it is founded at $-40 \mathrm{~m}$ for the 12-h band. On the contrary, during the other two deployments, the energy spectrum for both bands is weak at the surface. The 24-h band shows the maximum energy spectrum at $-40 \mathrm{~m}$, while the $12-\mathrm{h}$ band at the deepest layers.

The value given by ADCP is an average of the backscattering field consisting of both migrating and stationary organisms. Furthermore each migrating species has its own behavior that may change during the different stages of life and due to environmental conditions. Thus, these results may suggest the contemporaneous presence of different types of zooplankton organisms, some are migrants, each according to its own specific DVM pattern, while others are more stationary. Depending on the prevalence of one or another organism, the DVM signal may be more or less detectable.

Several studies [22][23][24][25][26][27] point out that the Ligurian Sea is characterized by different zooplankton populations whose distribution is related to the main hydrological features of this basin. The characteristics of the water masses underwent major changes over the three years in question and this is further confirmed by the analysis of the horizontal currents recorded by the ADCP. Marine circulation changes significantly between 2003 and 2006, turning from North to West and decreasing in intensity (Fig. 8).
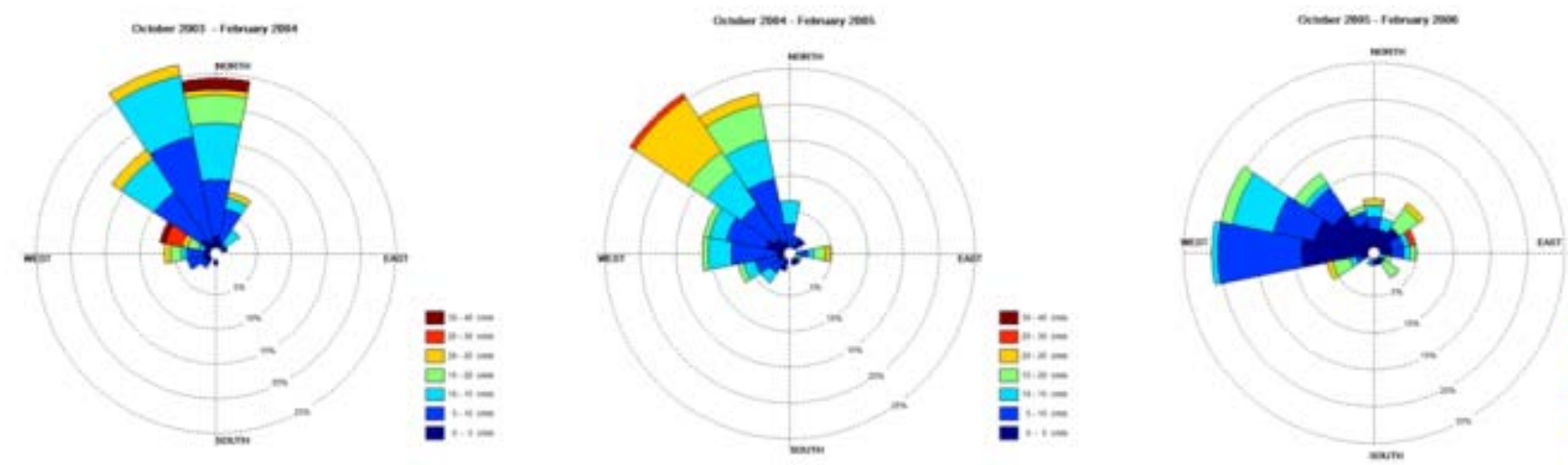

Fig. 8. Distribution of the horizontal currents during the three deployments in the common period between October and Febraury. 
During the first period the flux is mainly direct towards North-Northwestern and only sporadically weak southward currents are recorded. On average, the mean hourly velocities are greater than $15 \mathrm{~cm} / \mathrm{sec}$, sometimes with peaks in the surface layers exceeding $60 \mathrm{~cm} / \mathrm{sec}$. On the contrary, during the third deployment, the average of the hourly velocity is less than 10 $\mathrm{cm} / \mathrm{sec}$ at all depths and the maximum values never raise above $45 \mathrm{~cm} / \mathrm{sec}$. The prevailing current is direct to West while the occurrences of southward fluxes increase. These different patterns of marine circulation may explain part of the differences between the three time series.

A further contribution to the high observed variability may be ascribed to the influence of the lunar cycle on the zooplankton behavior.

Fig. 9 shows hourly averaged values of the backscatter strength between moonrise and moonset (red) and between moonset and moonrise (black) for the three periods at the common depth of $-40 \mathrm{~m}$.

The moon cycle is well marked in both distributions, particularly for the data collected during the third deployment that have been acquired with a better temporal resolution. The data averaged between moonrise and moonset achieve the maximum in correspondence of the full moon and then decrease until they reach the minimum with the new moon. The cycle is opposite for the data averaged between moonset and moonrise. This behavior is observed at all depths, slightly more pronounced at the depth $-40 \mathrm{~m}$.

Although the light is generally referred as to be the most important cause of the vertical movement, some studies ([28], [29], [30]) suggest that there is a lunar rhythm in the behavior of many zooplankton species, mainly linked to their reproductive phase.
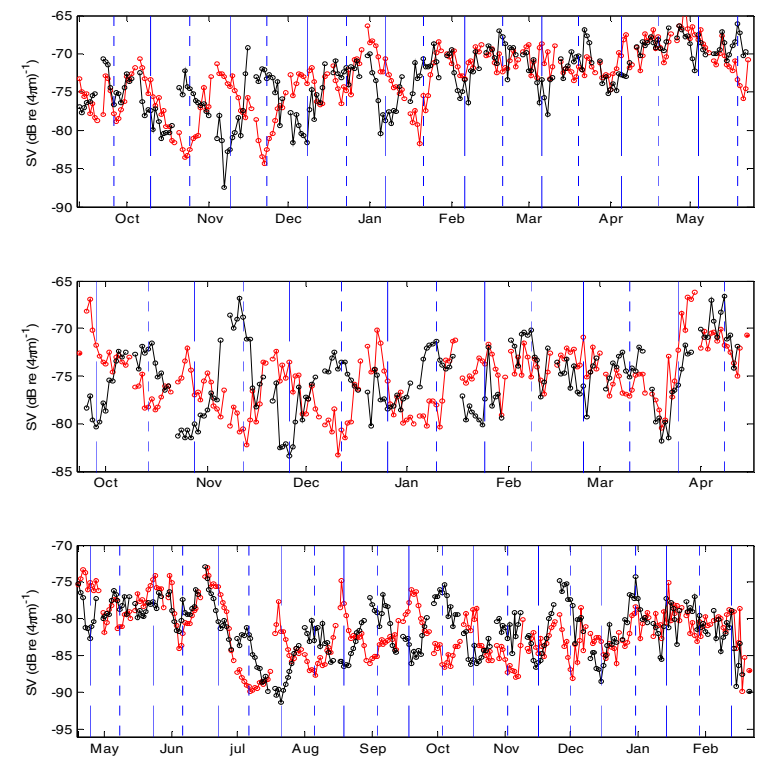

Fig. 9. Sv daily data averaged between moonrise and moonset (red) and between moonset and moonrise (black) in the three deployment at the depth of about $-40 \mathrm{~m}$. Full moon dashed line, new moon dotted line.

\section{CONCLUSION}

The analysis of the long time series of backscatter strength data obtained by an ADCP moored in the Ligurian Sea, allow to reveal some characteristics of the local zooplankton. In particular, the significant seasonal and interannual variability of both amount and composition of the zooplankton population may be partially ascribed to changes in the marine circulation of the basin. Furthermore, these data confirm the existing strong correlation between the behavior of the zooplankton and the lunar phases.

Since the end of 1980's, the Acoustic Doppler Current Profiler proved to be a very powerful instrument also in the field of marine biology. Although more qualitative than quantitative, the obtained results demonstrate that very useful information on the zooplankton may be extracted even if the instrument has not been deployed specifically for this purpose. Taking into account that long time series of ADCP data have been collected in many different ocean sites, their reexamination in terms of zooplankton variability can really improve the knowledge overcoming the difficulties related to other types of monitoring.

\section{ACKNOWLEDGMENT}

The research leading to these results has received part of the funding from the Italian Ministry of Education, University and Research within the National Program for Research in Antarctica under the grant agreement $n^{\circ} 2010 / A 4.01$.

\section{REFERENCES}

[1] T. P. Rippeth, and J. H. Simpson, "Diurnal signals in vertical motions on the Hebridean Shelf," Limnology and Oceanography., vol. 43(7), pp. 1690-1696, 1998.

[2] J. M. Pinot and J. Jansá, "Time variability of acoustic backscatter from zooplankton in the Ibiza Channel (western Mediterranean)," Deep-Sea Res. I, vol. 48, pp. 1651-1670, 2001.

[3] S. Jiang, T. Dickey, D. Steinberg, and L. Madin, "Temporal variability of zooplankton biomass from ADCP backscatter time series data at the Bermuda Testbed Mooring Site," Deep Sea Research, vol. I(54), pp. 608-636, 2007.

[4] C. J. Ashjian S. L. Smith, C. N. Flagg, A. J. Mariano, Behrens and P. V. Z. Lane, "The influence of a Gulf Stream meander on the distribution of zooplankton biomass in the Slope Water, the Gulf Stream, and the Sargasso Sea, described using a shipboard acoustic Doppler current profiler," Deep-Sea Research I, vol. 41, pp. 23-50, 1994.

[5] C. J. Ashjian, S. L. Smith, C. N. Flagg and N. Idrisi, "Distribution, annual cycle, and vertical migration of acoustically derived biomass in the Arabian Sea during 1994-1995," Deep-Sea Research II, vol. 49, pp. 2377-2402, 2002.

[6] H. van Haren, "Echo intensity data as a directional antenna for observing processes above sloping ocean bottoms," Ocean Dynamics, vol. 57, pp. 135-149, 2007.

[7] C. M. Flagg, and S. L. Smith, "On the use of the Acoustic Doppler Current Profiler to measure zooplankton abundance.," Deep-Sea Research I, vol. 36, pp. 455-474, 1989.

[8] A .J. Plueddemann and R. Pinkel, "Characterization of the patterns of diel migration using a Doppler sonar," Deep-Sea Research I, vol. 36, pp. 509-530, 1989 .

[9] S. Fielding, G. Griffiths and H. S. J. Roe, "The biological validation of ADCP acoustic backscatter through direct comparison with net samples and model predictions based on acoustic-scattering models," Journal of Marine Sciences, vol. 61( 2), pp. 184-200, 2004.

[10] P. Picco, A. Cappelletti, S. Sparnocchia, M. E. Schiano, S. Pensieri and R. Bozzano, "Upper Layer current variabilità in the Central Ligurian 
Sea," Ocean Science, vol. 6, pp. 825-836, 2010.

[11] M. Visbeck and J. Fischer, "Sea surface conditions remotely sensed by upward-looking ADCPs," Journal of Atmospheric and Oceanic Technology, vol. 12, pp. 141-149, 1995.

[12] WinRiver. User's Guide, International Version., P/N 957-6171-00, RD Instruments, April 2003.

[13] F. Schott and K. D. Leaman, "Observations with moored acoustic Doppler current profilers in the convection regime in the Golfe du Lion,” Journal of Physical Oceanography, vol. 21, pp. 558 -574, 1991.

[14] K. L. Deines, "Backscatter estimation using broadband acoustic Doppler current profilers," Proc. Sixth Working Conf. on Current Measurement, San Diego, CA, IEEE, pp. 249-253, 1999.

[15] M. A. Ainslie and J. G. McColm, "A simplified formula for viscous and chemical absorption in seawater," Journal of the Acoustical Society of America, vol. 103(3), pp. 1671-1672, 1998.

[16] J.M. Brankart, N. Pinardi, "Abrupt Cooling of the Mediterranean Levantine Intermediate Water at the Beginning of the 1980s: Observational Evidence and Model Simulation," Journal of Physical Oceanography, vol. 31, pp. 2307-2320, 2001.

[17] K. V. Mackenzie, "Nine-term equation for sound speed in the oceans Journal of the Acoustical Society of America, Vol. 70, Issue 3, pp. 807$812,1981$.

[18] R. L. Gordon, “Acoustic Doppler Current Profilers Principles of Operation: A Practical Primer,” RD Instruments, 54, 1996

[19] F. Schott, "Measuring winds from underneath the ocean surface by upward looking acoustic Doppler current profilers," Journal of Geophysical Research, vol. 94, pp. 8313-8321, 1989.

[20] L. Gostiaux, and H. van Haren, "Extracting meaningful information from uncalibrated backscattered echo intensità data," Journal of Atmospheric and Oceanic Technology, vol. 27, pp. 943-949, 2010.

[21] A. Lane,. P. J. Knight, and R. J. Player, "Current Measurement Technology for Nearshore Waters," Coastal Engineering, vol. 37, pp. 343-368, 1999.
[22] J. Boucher, F. Ibanez, and L. Prieur, "Daily and seasonal variations in the spatial distribution of zooplankton populations in relation to the physical structure in the Ligurian Sea front," Journal of Marine Sciences, vol. 45, pp. 133-173, 1987.

[23] P. Licandro and F. I. Banez, "Changes of zooplankton communities in the Gulf of Tigulio (Ligurian Sea, western Mediterranean) from 1985 to 1995. Influence of hydroclimatic factors," Journal of Plankton Research, vol. 22, pp. 2225-2253, 2000.

[24] P. Licandro, and P. Icardi, "Basin scale distribution of zooplankton in the Ligurian Sea (north-western Mediterranean) in late autumn," Hydrobiologia, vol. 617, pp.17-40, 2009.

[25] D. E. Mcgehee, D. A. Demer and J. D. Warren, "Zooplankton in the Ligurian Sea: Part I. Characterization of their dispersion, relative abundance and environment during summer 1999,' J. Plankton Res., vol. 26(12), pp. 1409-1418, 2004.

[26] M. L. Fernandez de Puelles and, J. C. Molinero, "Decadal changes in hydrographic and ecological time-series in the Balearic Sea (western Mediterranean), identifying links between climate and zooplankton," ICES Journal of Marine Science, vol. 65, pp. 311-317, 2008.

[27] V. Raybaud, P. Nival, L. Mousseau, A. Gubanova, D. Altukhov, S. Khvorov, F. Ibanez, and V. Andersen, "Short term changes in zooplankton community during the summer-autumn transition in the open NW Mediterranean Sea: species composition, abundance and diversity," Biogeosciences, vol. 5, pp. 1765-1782, 2008.

[28] Z. M. Gliwicz, “A lunar cycle in zooplankton,” Ecology, vol. 67, pp. 883-897, 1986.

[29] G. A. Tarling, F. Buchholz and J. B. L. Matthews, "The effect of a lunar eclipse on the vertical migration behaviour of Meganyctiphanes norvegica (Crustacea: Euphausiacea) in the Ligurian Sea," Journal of Plankton Research, vol. 21, pp. 1475-1488, 1999.

[30] K. J. Benoit-Bird, W. W .L. Au, and D.W. Wisdom, "Nocturnal light and lunar cycle effects on diel migration of micronekton," Limnology and Oceanography, vol. 54, pp. 1789-1800, 2009. 